\title{
DEGRADATIVE STUDIES ON A SOIL HUMIN FRACTION-SEQUENTIAL DEGRADATION OF INHERITED HUMIN
}

\author{
G. Almendros \\ Instituto de Edafologia y Biología Vegetal, Serrano 115 dpdo., 28006 Madrid, Spain \\ and \\ F. J. GonzÁlez-Vila \\ Centro de Edafología y Biologia Aplicada del Cuarto, P.O.B. 1052, Sevilla, Spain
}

(Accepted 20 December 1986)

\begin{abstract}
Summary-Degradation products of soil humin preparations from three different soil types were studied. Inherited humin was isolated by ultrasonic treatment and densimetry of the heavy fraction of soil, and purified by treatment with dilute alkali and acid and exhaustive lipid extraction. These purified humins, which represented $10-26 \%$ of the total soil C (34-55\% of total alkali-insoluble humified C), were degraded with potassium persulfate followed by alkaline permanganate oxidation. The degradation products obtained (identified by GC-MS as methyl derivatives) were fatty acids, dicarboxylic aliphatic acids, benzenecarboxylic acids, phenolic acids and alkanes.

An unexpectedly high proportion of polymethylene compounds (mainly fatty acids) were observed in the humins of the three soils, in both loosely and strongly associated forms. It is considered that these aliphatic chains are stable humin constituents, physically or chemically associated with a highly oxidized, demethoxylated and disordered matrix entrapping a significant proportion of non-polar compounds. Some of the aliphatic components seem to be inherited from cuticular waxes of higher plants, but it is tentatively suggested that during the microbial reworking of lignins the lipid polymers were altered, then contributing to the formation of humin.
\end{abstract}

\section{INTRODUCTION}

While the alkali-extractable humic substances (humic and fulvic acids) have been extensively studied, the insoluble humin fractions have received little attention. Alkali-insoluble humins often represent the most abundant organic fraction in soils, but their complete isolation or quantitative determination is problematic due to their heterogeneous nature and their strong physical and chemical linkages to the mineral components.

Classical concepts consider soil humins as nonextractable humic fractions firmly associated to mineral fractions by strong linkages that cannot be removed by the usual alkaline reagents. When studied as a whole, several authors have suggested a nearly identical composition of soil humin to that of extractable humic fractions (Kononova, 1961; Schnitzer and Khan, 1972).

Another criterion, (Duchaufour and Jacquin, 1975; Chouliaras et al., 1975), is that soil humin can be partially isolated (after densimetric separation of the undecomposed plant debris) by ultrasonic disruption of soil microaggregates, liberating the so-called inher ited humin.

Inherited humin is considered to be an altered lignin-like polymer (Vedy, 1973; Toutain, 1974). According to this hypothesis, after selective biodegradation of the plant components less resistant to microbial attack, soil lignin is transformed into humic-like material by means of the so called direct humification processes (no soluble phases involved).
During these reactions, originally described by Waksman (1936), insoluble lignins undergo demethoxylation and carboxylation, and nitrogencontaining components are incorporated (Duchaufour and Jacquin, 1975; Dupuis and Cheverry, 1973; Almendros et al., 1981). The resulting material is composed of very small or microscopic (subcellular) particles retained in the soil microaggregates.

While the origin of this type of humin is closely related to the alteration processes of plant biopolymers, the neoformation (insolubilized) humins are considered to be formed by polymerization of soluble precursors in soils (Duchaufour and Jacquin, 1975). This latter humin fraction is comprised of an extract able type (humic and fulvic acids solubilized in the laboratory after demineralization treatments; Merlet, 1971) and a non-extractable fraction.

Since the application of non-destructive techniques gave little information on the nature of these inherited humin fractions (Almendros et al., 1980b, 1981), and showed a complex composition, a degradative study after exhaustive purification of this humin fraction is proposed.

\section{MATERIALS AND METHODS}

\section{Soil organic matter fractions}

Inherited humin was isolated from the Al horizon of three forest soils with different vegetation and climates (Almendros et al., 1980a): sample $\mathrm{A}=$ Typic 
Xerocherpt; sample B = Dystric Xerochrept; sample $\mathrm{C}=$ Typic Haplorthod. Soil characteristics and humus fractions are given in Table 1.

Non-decomposed plant residues (free organic matter) were removed after shaking soil samples (sieved $<2 \mathrm{~mm}$ ) in $\mathrm{CHBr}_{3}-\mathrm{EtOH}$ mixtures with a density of 1.8 (Monnier et al., 1962). This operation was repeated until no floating particles were observed.

Soil residue (heavy fraction) was dispersed again in the densimetric liquid, and disaggregated with a Branson, Sonifier B-12 ultrasonic generator. After centrifugation, the suspended fraction ("crude inherited humin") was filtered and washed with ethanol, and the ultrasonic and densimetric treatments were repeated 4 times.

The new heavy soil residue was dried and extracted with $0.1 \mathrm{M} \mathrm{Na} \mathrm{N}_{2} \mathrm{O}_{7}$ and $0.1 \mathrm{M} \mathrm{NaOH}$ under $\mathrm{N}_{2}$ (shaking $1 \mathrm{~h}$ at room temperature, $\times 6$ ) for the extraction of humic and fulvic acids, the former being precipitated with $\mathrm{HCl}$ to $\mathrm{pH}$ 1. The soil residue was then submitted to 2 treatments with $60 \mathrm{mM} \mathrm{Na} \mathrm{Na}_{2} \mathrm{O}_{4}$ and 4 treatments with $1 \mathrm{M} \mathrm{HCl}-\mathrm{HF}(1: 1)$ at $60^{\circ} \mathrm{C}$ (Merlet, 1971). A new treatment with $0.1 \mathrm{M} \mathrm{NaOH}$ yielded an iron-clay bonded humic fraction (extractable humin) (Scheme 1).

\section{Purification of samples}

Since the "crude inherited humins" are composed of a mixture of "pure humin" with a certain proportion of humic and fulvic acids, bitumen and minerals (Almendros et al., 1980b), a purified humin preparation was obtained. Humic and fulvic acids were extracted by 5 treatments with $0.1 \mathrm{M} \mathrm{NaOH}$ under $\mathrm{N}_{2}$, and discarded. The residue was demineralized with $0.1 \mathrm{M} \mathrm{HCl}-\mathrm{HF}(1: 1)$, then suspended in toluene and dispersed with the ultrasonic disruptor. Extraction was continued $(12 \mathrm{~h})$ in a Blount micro-extractor with the same solvent. This operation was repeated over 1 week using fresh solvent, and toluene extracts were concentrated under reduced pressure.

\section{Degradative studies}

Purified humin was submitted to sequential degradation with two reagents commonly used for oxidation of humic acids and lignins. After acid oxidation with persulfate (a mild procedure removing the more easily degradable organic constituents) (Martin et al., 1981), the non-degraded residue was oxidized with potassium permanganate, (Matsuda and Schnitzer, 1972). The digests obtained were extracted with hot ethyl acetate, dried under reduced

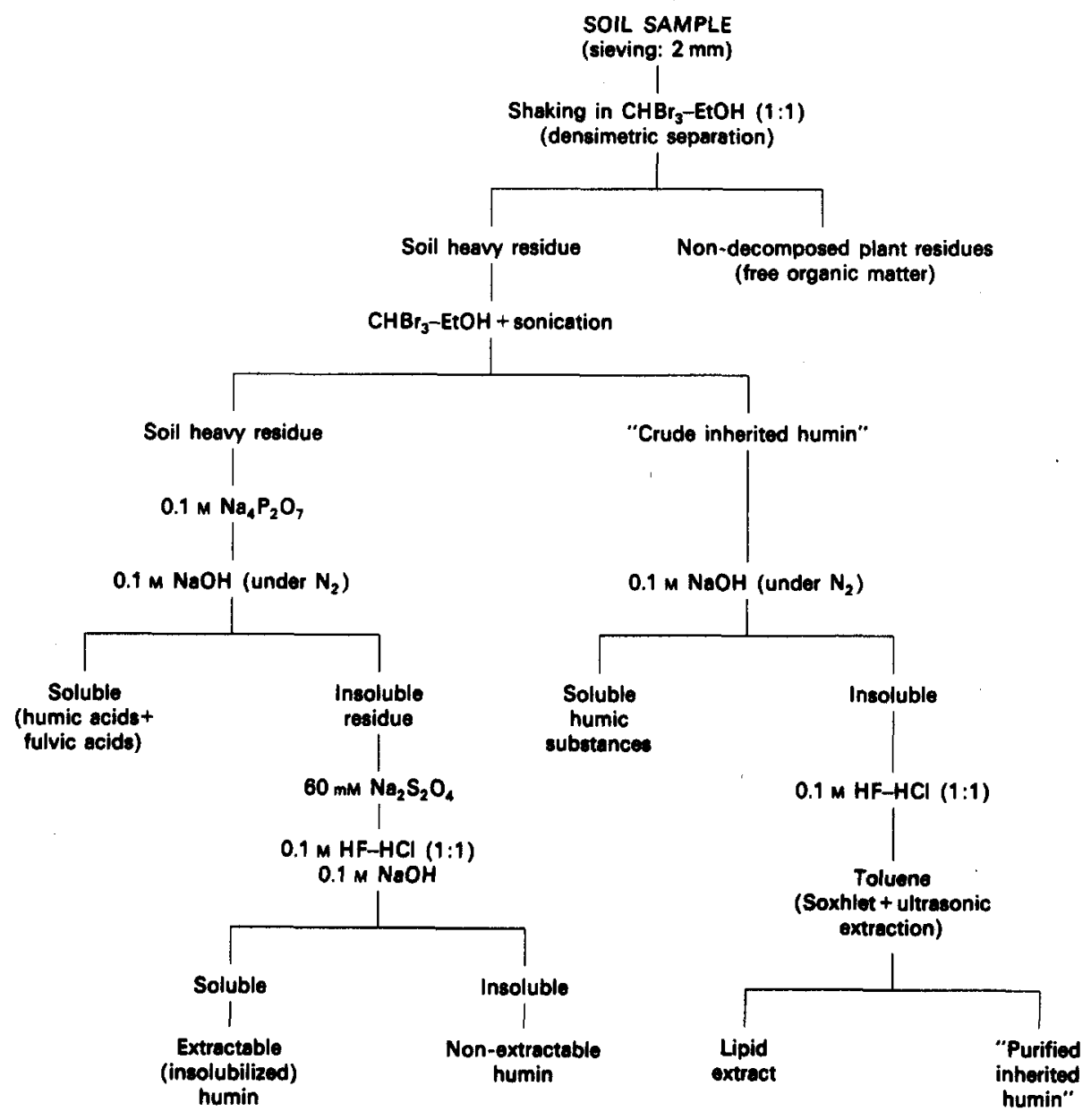

Scheme 1. Experimental procedure for isolation and purification of humin. 
pressure, suspended in methanol and methylated with diazomethane (Schnitzer, 1974). Methylated samples were then injected in a Hewlett-Packard 5992 GC-MS equipped with a $25 \mathrm{~m}, 0.2 \mathrm{~mm}$ i.d., crosslinked OV-101 capillary Hewlett-Packard column.

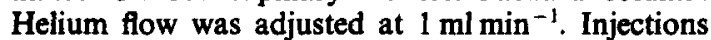
were of $1-1.5 \mu \mathrm{l}$ of sample diluted in $1-2 \mathrm{ml}$ of chloroform (splitless mode, injection port temperature $=270^{\circ} \mathrm{C}$ ). Oven temperature was $40^{\circ} \mathrm{C}$ at injection, raising to $100^{\circ} \mathrm{C}$ at $32^{\circ} \mathrm{C} \mathrm{min}^{-1}$, then programmed at $6^{\circ} \mathrm{C} \mathrm{min}{ }^{-1}$ between 100 and $270^{\circ} \mathrm{C}$. Peak identification was carried out by matching in the computer libraries and by comparison with standards and also with data in the bibliography. Mass spectra were recorded in the 40-400 range, and ion of $m / z 74$ was simultaneously monitored for direct identification of the fatty acids methyl esters. No absolute quantitative data was given, but the amounts of compounds were considered as proportional to the response of a f.i.d. in a Hewlett-Packard 5730A gas chromatograph with the same column (Maximov et al., 1977).

\section{RESULTS}

The quantitative importance of inherited humin is shown in Table 1. This soil fraction represented more than $50 \%$ of the total humin in soils B and C. In soils $A$ and $B$, inherited humin was more abundant than humic acids, and in the three soils studied, this humin fraction predominated over the fulvic acids. Insolubilized humin was not abundant in these soils and, as in the case of the non-extractable humin, predominated in humus types of higher activity (A > B > C). (Duchaufour and Jacquin, 1975).

Organic compounds identified after the progressive treatments are shown in Figs 1-3 and in Tables 2 and 3. The lipid fractions obtained from humin after ultrasonic treatment in toluene were not considered a "non-huminic" constituents: although these lipid fractions are probably not bonded chemically to humin, the previous extraction of the free lipids of soils during the treatments with bromoform and ethanol followed by extractions with alkali, suggested that the compounds in these toluene extracts were more firmly associated to humin than to the heavy soil fraction. For this reason, these extracts were also methylated and studied by GC-MS; they are considered as the more superficial or loosely joined constituents of the inherited humin.

Ultrasonic disruption and toluene extraction removed long-chain aliphatic compounds. The quantitative proportions of alkanes and fatty acids were difierent in the soils studied, but the principal compounds identified were essentially the same.

The persulfate degradation products included aromatic acids (phenolic and benzenecarboxylic), but the predominant peaks corresponded to aliphatic compounds (palmitic and stearic acids, compounds No. 33 and 45). Dimethoxy benzenecarboxylic acid, probably a lignin-derived product, was present in humin from the three soil samples, but the proportion of aromatic compounds was low in comparison with the predominant peaks of the $14-25 \mathrm{C}$ fatty acids and the $14-26 \mathrm{C}$ alkane series.

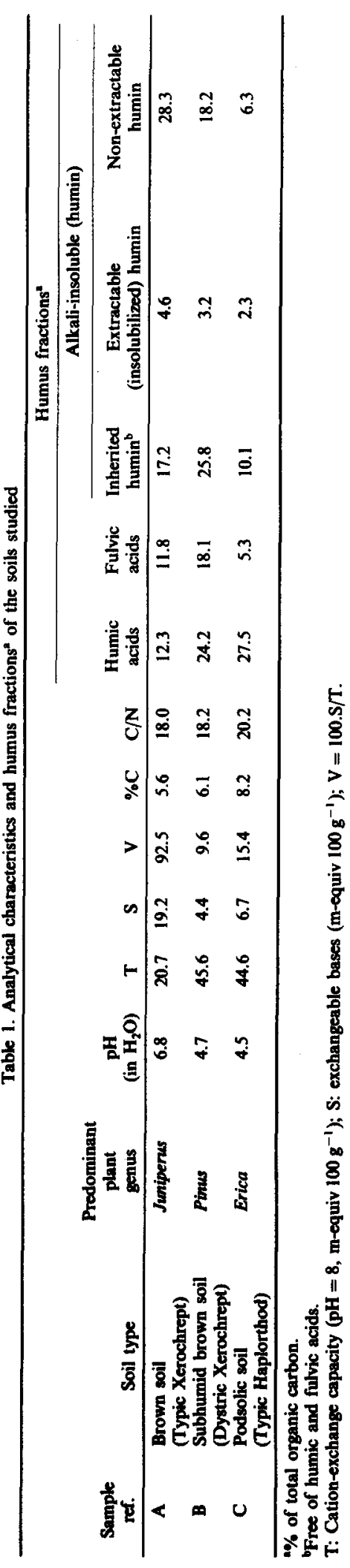


Table 2. Organic compounds' separated after sequential treatments of humins

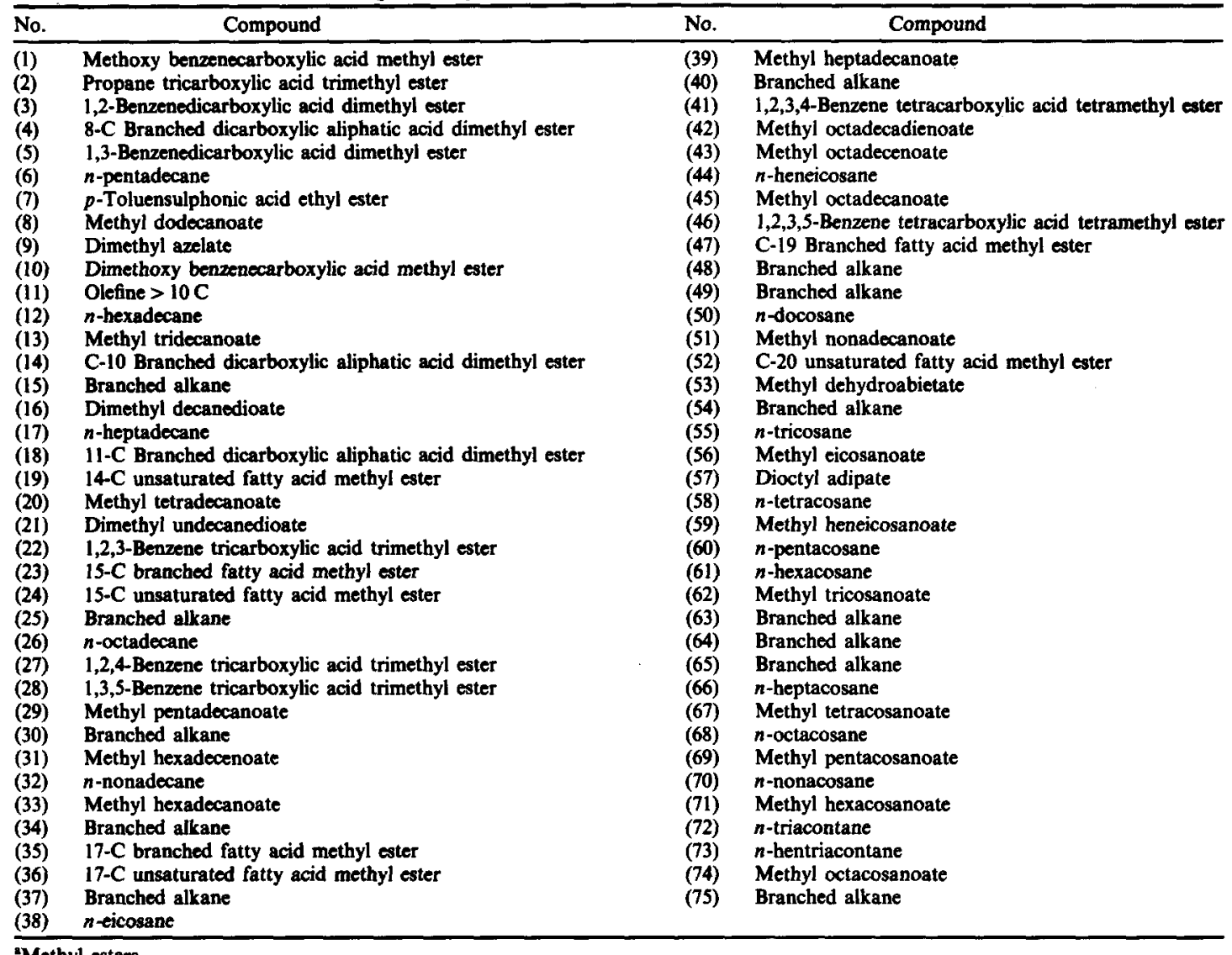

Methyl esters.

Aromatic constituents were more abundant in the permanganate digests, but they represented no more than $30 \%$ of the total amount of compounds identified. The permanganate degradation products showed greater differences than those from the toluene and persulfate treatments. In the more active humus type (soil $\mathbf{A}$ ), aromatic products showed a high degree of oxidation, and no phenolic groups were detected. Benzene di-, tri- and tetracarboxylic acids were present. The proportion of dicarboxylic aliphatic acids was low in this sample, and fatty acids were the most abundant oxidation products.

In the subhumid brown soil (B), fatty acids and alkanes were less abundant, but dicarboxylic aliphatic acids constituted $32 \%$ of the total oxidation products. Benzenecarboxylic acids were not abundant, but phenolic acids were present (methoxy benzenecarboxylic acids represented $4.5 \%$ of the oxidation products). Propane tricarboxylic acid was also present and in a higher proportion than in sample $A$.

In the podsolic soil (C), aromatic acids were the most abundant (almost $30 \%$ of the total degradation products). Dicarboxylic aliphatic acids were about $7 \%$ of the total oxidation products, and phenolic acids were not detected.

A comparison of the total percentages of different types of degradation products (Table 3 ) showed the effects of progressive treatments. Most of the alkanes (22-46\% of the toluene extract) are probably not true "building blocks" of humins, but they could be loosely entrapped in the internal surfaces of the altered structures. A low percentage are joined to humin in the persulfate-removable forms (about $20 \%$ ), and a small amount (amount $3 \%$ of the permanganate digest) are strongly associated to humin, probably entrapped by steric impediments at a molecular level. In all the samples studied, the alkanes observed seem to be inherited. A tendency was observed for the predominance of the odd carbon number homologues, which was also observed for the chains with more than $20 \mathrm{C}$ atoms, which may correspond to a significant contribution from wax constituents of higher plants (Simoneit et al., 1980; Simoneit and Mazurek, 1982). Higher mol. wt homologues $(>26 \mathrm{C}$ ) were more frequent in the toluene extracts, but after degradation, the maximum chain lengths were always near $\mathrm{C}-23$.

In the case of fatty acids, the total amounts obtained after degradation (persulfate or permanganate) were greater than those found in the toluene extract, which suggests that they are joined to the humin by more efficient mechanisms than merely physical ones (Table 3). It is remarkable that they are also abundant even in the permanganate digest, indicating that these predominant products were indeed a constituent of humins. The ratio of fatty acids to alkanes varied significantly according to the stage of degradation: fatty acids were more abundant 

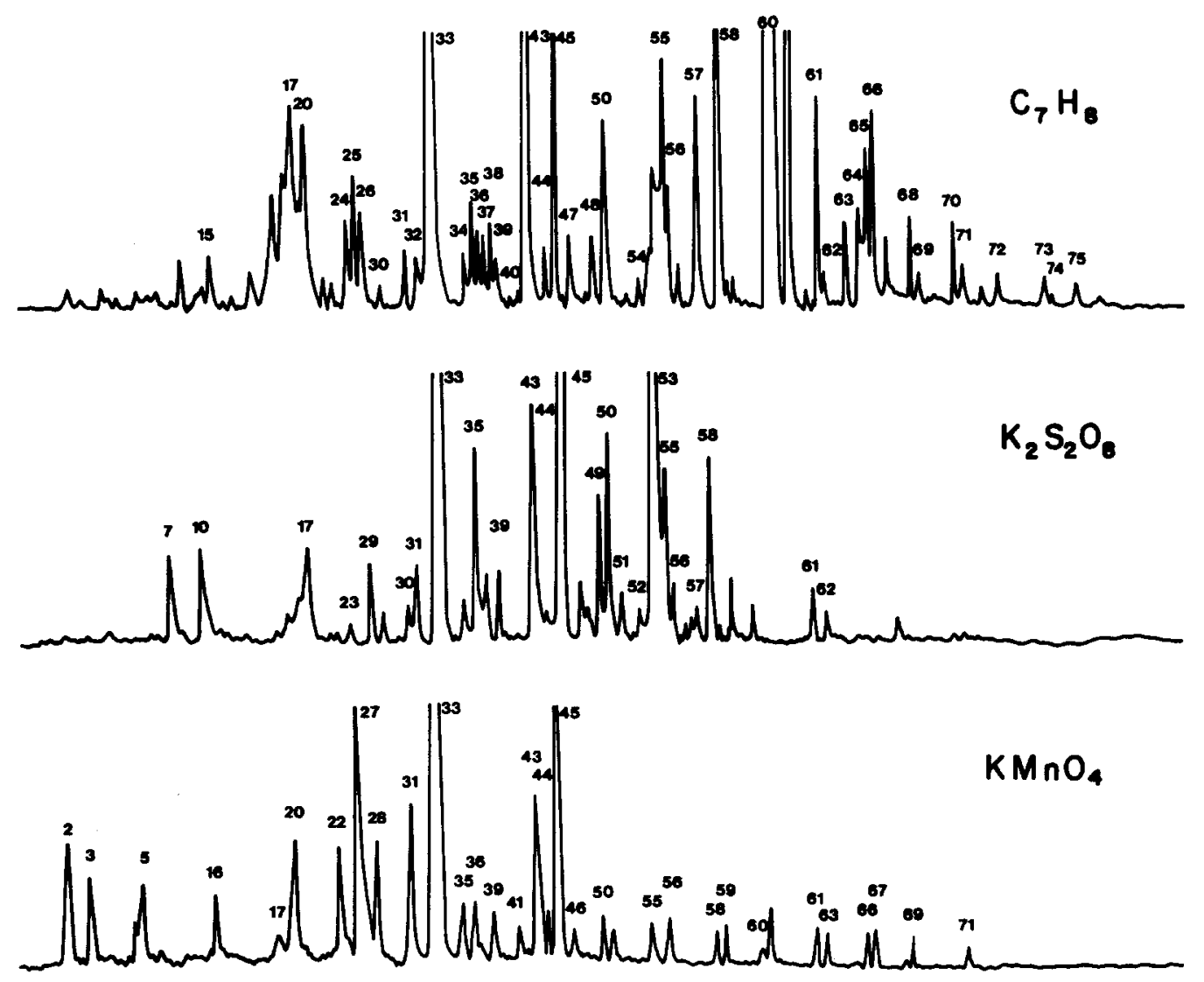

\begin{tabular}{lllllll}
\hline 5 & 10 & 15 & 20 & 25 & 30 & $\mathrm{~min}$
\end{tabular}

Fig. 1. Gas chromatographic separation (f.i.d.) of products obtained after sequential treatments of inherited humin from brown soil under Juniperus sp. [(1) Ultrasonic-hot toluene; (2) acid persulfate oxidation; (3) alkaline permanganate oxidation].

in the strongly joined forms (toluene < persulfate $<$ permanganate). The homologous series of fatty acids seem to be independent of those of alkanes. A small quantity of the chains with more than $20 \mathrm{C}$ atoms was observed; these homologues were clearly present only in the toluene extract. After degradation, the $\mathrm{C}-16$ and $\mathrm{C}-18$ fatty acids gave the largest peaks, and the higher homologues, presumably contained in cuticular waxes were not represented, or their proportion was not significant (Grimalt et al., 1984).

\section{DIsCUSSION}

The study of the low molecular weight products obtained after progressive degradation of inherited humin showed a significant aliphatic content; monoor dicarboxylic aliphatic acids predominated over the aromatic products in three types of humus with different vegetation and biological activity.

The high aliphatic content of these insoluble fractions, hypothetically formed during alteration of lignin, is noteworthy. The presence of these longchain compounds is more significant considering that they were obtained after lipid extraction and alkali treatment (removal of humic and fulvic acids), exhaustive ultrasonic treatment in toluene and persulfate degradation, indicating that they are strongly joined to a stable heteropolymer by chemical linkages or very efficient steric impediments. These data can be explained by assuming that these microbiallyreworked biopolymers has an increased ability for the physical and chemical incorporation of new constituents in relatively stable forms (e.g. hydrocarbons, lipids, nitrogen compounds ...). Though most of the alkanes $(3-5 \%$ of permanganate degradation products) may be inherited, the very abundant proportion of saturated and unsaturated fatty acids (36-62\% of the permanganate digest) may be of microbial origin, introduced during the biological transformation of lignin, and would probably be incorporated in esters with the naturally oxidized lignins. Nevertheless, the aliphatic content was higher than those of most of the humic acids, and a contribution of altered lipid polymers to the composition of humin is tentatively suggested. Although the degradation techniques employed were not specific for polyester compounds, the observed chain lengths were also typical of certain constituents of higher plants such as cutins and suberins (Kolattukudy, 1977). These resistant sub- 

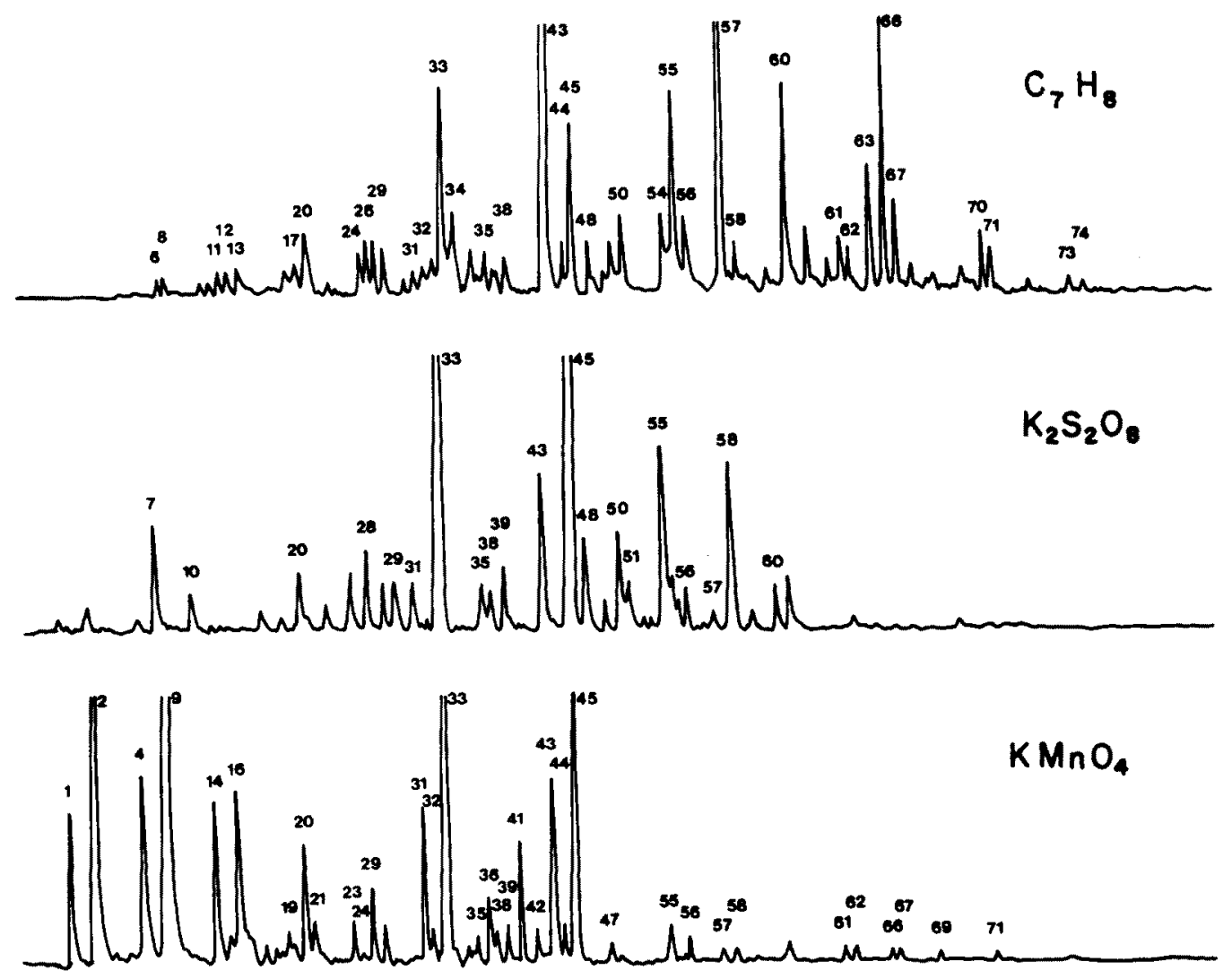

\begin{tabular}{lllllll}
\hline 5 & 10 & 15 & 20 & 15 & 30 & min
\end{tabular}

Fig. 2. Gas chromatographic separation (f.i.d.) of products obtained after sequential treatments of inherited humin from subhumid brown soil under Pinus sp. [(1) Ultrasonic-hot toluene; (2) acid persulfate oxidation; (3) alkaline permanganate oxidation].

Table 3. Total abundances and relations between different groups of degradation products ( $\%$ of the total volatile compounda)

\begin{tabular}{|c|c|c|c|c|c|c|c|c|c|}
\hline \multirow{2}{*}{$\begin{array}{l}\text { Treatment } \\
\text { Soil sample }\end{array}$} & \multicolumn{3}{|c|}{$\begin{array}{l}\text { Ultrasonic disruption } \\
\text { in toluene }\end{array}$} & \multicolumn{3}{|c|}{$\mathrm{K}_{2} \mathrm{~S}_{2} \mathrm{O}_{8}$} & \multicolumn{3}{|c|}{$\mathrm{KMnO}_{4}$} \\
\hline & A & B & C & $\mathbf{A}$ & B & C & A & B & C \\
\hline $\begin{array}{l}\text { Dicarboxylic aliphatic acids" } \\
\text { Total alkanes } \\
\text { Branched alkanes } \\
\text { Alkane range } \\
\text { Total fatty acids" } \\
\text { Unsaturated fatty acids } \\
\text { Branched fatty acids" } \\
\text { Fatty acids range } \\
\text { Total aromatics" } \\
\text { Phenolic acids } \\
\text { Benzenecarboxylic acids" } \\
\text { Unidentifed } \\
\text { Aliphatica-to-aromatics } \\
\text { Benzenecarboxylic-to-phenolics } \\
n \text {-alkanes-to-b-alkanes } \\
2 n \text { alkanes-to-2n+1 alkanes } \\
>20 \mathrm{C} \text { alkanes-to-<20 C alkanes } \\
n \text {-fatty acids-to- } b \text {-fatty acids } \\
\text { Saturated fatty acids-to-unssturated } \\
\text { fatty acids } \\
2 n \text { fatty acids-to- } 2 n+1 \text { fatty acids } \\
>20 \mathrm{C} \text { fatty acids-to-<20 C fatty acids } \\
\text { Fatty acida-to-alkanes }\end{array}$ & $\begin{array}{c}0.00 \\
46.32 \\
7.12 \\
17-31 \\
28.73 \\
9.50 \\
1.22 \\
14-28 \\
0.00 \\
0.00 \\
0.00 \\
16.96\end{array}$ & $\begin{array}{c}0.00 \\
41.32 \\
7.75 \\
15-31 \\
34.80 \\
12.23 \\
0.34 \\
12-28 \\
0.00 \\
0.00 \\
0.00 \\
11.56\end{array}$ & $\begin{array}{c}0.00 \\
22.34 \\
3.57 \\
17-31 \\
49.24 \\
18.53 \\
1.39 \\
15-28 \\
0.00 \\
0.00 \\
0.00 \\
23.18\end{array}$ & $\begin{array}{c}0.00 \\
20.07 \\
3.00 \\
17-26 \\
61.95 \\
12.81 \\
7.02 \\
15-23 \\
11.89 \\
1.92 \\
0.00 \\
5.27 \\
6.97 \\
\\
5.69 \\
2.19 \\
4.87 \\
7.82\end{array}$ & $\begin{array}{c}0.00 \\
23.93 \\
3.69 \\
14-20 \\
57.05 \\
8.07 \\
2.32 \\
14-20 \\
5.47 \\
0.96 \\
1.78 \\
12.59 \\
14.98 \\
1.85 \\
5.49 \\
1.69 \\
18.46 \\
23.59\end{array}$ & $\begin{array}{c}0.00 \\
24.78 \\
0.00 \\
20-26 \\
64.43 \\
4.63 \\
2.59 \\
14-25 \\
2.50 \\
0.81 \\
0.00 \\
8.29 \\
35.68\end{array}$ & $\begin{array}{c}2.21 \\
4.63 \\
0.00 \\
17-27 \\
61.62 \\
14.07 \\
1.23 \\
14-26 \\
25.55 \\
0.00 \\
25.55 \\
2.30 \\
2.82\end{array}$ & $\begin{array}{c}31.94 \\
2.78 \\
0.00 \\
19-27 \\
35.56 \\
9.29 \\
3.57 \\
14-26 \\
10.46 \\
4.46 \\
6.00 \\
1.78 \\
8.39 \\
1.35\end{array}$ & $\begin{array}{c}6.93 \\
3.87 \\
0.00 \\
20-25 \\
45.93 \\
12.00 \\
6.52 \\
14-26 \\
28.62 \\
0.00 \\
28.62 \\
14.65 \\
1.98\end{array}$ \\
\hline
\end{tabular}

Methyl eaters. 

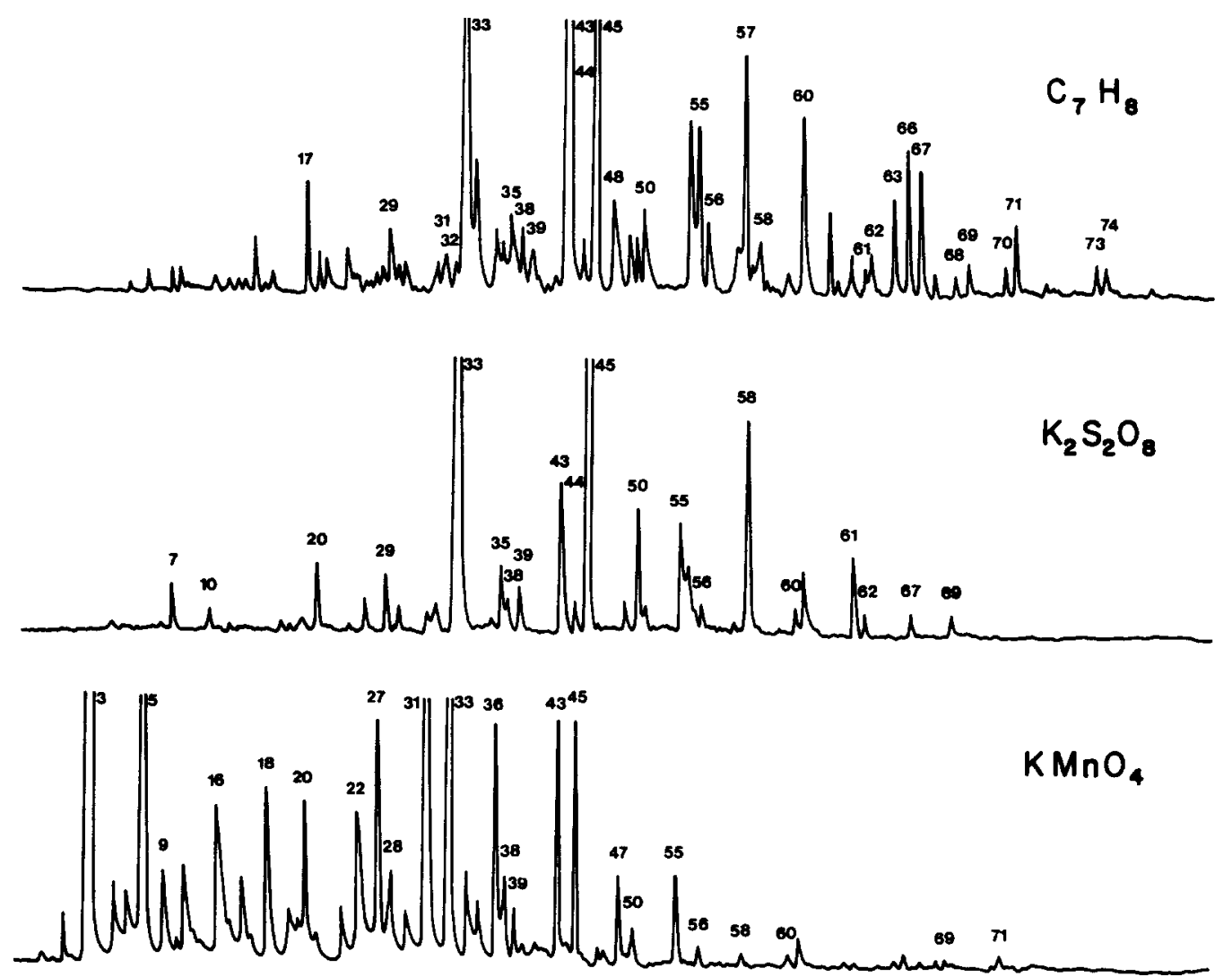

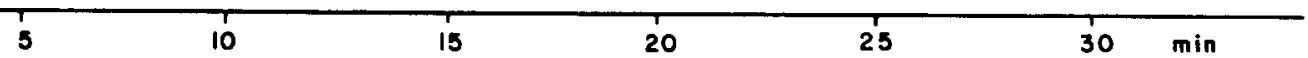

Fig. 3. Gas chromatographic separation (f.i.d.) of products obtained after sequential treatments of inherited humin from podzolic soil under Erica sp. [(1) Ultrasonic-hot toluene; (2) acid persulfate oxidation; (3) alkaline permanganate oxidation].

stances or their degradation products may also contribute to the high proportion of lipid components in the inherited humin; to obtain more information on insoluble humic materials it is necessary to use degradative techniques suitable for dealing with aliphatic components.

With regard to the aromatic products, the presence of an altered lignin-like polymer agrees with the results obtained, but the proportions of the characteristic phenolic constituents were low, similar to those described for suberins (Kolattukudy and Dean, 1974; Kolattukudy et al., 1975). However, the relatively low yields of phenolic acids may correspond to an extensive demethoxylation and oxidation of the original biopolymers.

\section{REFERENCES}

Almendros G., Polo A. and Dorado E. (1980a) Contribución al estudio de la humina heredada de los suelos. I. Distribución cuantitativa en diferentes tipos de suelo. Observación al microscopio electrónico de barrido. Agrochimica 24, 232-244.

Almendros G., Polo A. and Dorado E. (1980b) Contribución al estudio de la humina heredada de los suelos. II. Caracterización fisicoquimica. Agrochimica 24, 309-319.
Almendros G., Polo A. and Dorado E. (1981) Aislamiento y caracterización de la fracción de humina no extraible en diferentes tipos de suelo. Agrochimica 25, 479-491.

Chouliaras N., Vedy J. C., Jacquin F. and Portal J. M. (1975) Fractionnement et caractérisation de la matière organique dans les rendzines. Bulletin de l'Institut National Polytechnique Nancy 17, 65-74.

Duchaufour P. and Jacquin $F$. (1975) Comparaison des processus d'humification dans les principaux types d'humus forestiers. Bulletin de l'Association Franfaise pour l'Etude du Sol 1, 29-36.

Dupuis T. and Cheverry C. (1973) Etude de "l'humine" de vases lacustres et de sols des polders de bordure du lac Tchad. Cahiers ORSTOM, Serie Pédologie 11, 215-225.

Grimalt J., Albaiges J. and Simoneit B. R. T. (1984) Investigación de recursos energéticos fósiles mediante espectrometría de masas y técnicas complementarias. Quimica e Industria 30, 481-486.

Kolattukudy P. E. (1977) Biosynthesis and Degradation of Lipid Polymers. In Lipids and Lipid Polymers in Higher Plants (M. Tevini and H. K. Lichtenthaler, Eds), pp. 271-292. Springer-Verlag, Berlin.

Kolattukudy P. E. and Dean B. B. (1974) Structure, gas chromatographic measurement and function of suberin synthesized by potato tuber tissue slices. Plant Physiology 54, 116-121.

Kolattukudy P. E., Kroman K. and Poulose A. J. (1975) Determination of structure and composition of suberin from the roots of carrot, parsnip, rutabaga, turnip, red 
beet and sweet potato by combined gas-liquid chromatography and mass-spectrometry. Plant Physiology 55 , $567-573$.

Kononova, M. M. (1961) Soil Organic Matter. Pergamon Press, London.

Martín F., Saiz-Jiménez C. and González-Vila F. J. (1981) The persulfate oxidation of a soil humic acid. Soil Science 132, 200-203.

Matsuda K. and Schnitzer M. (1972) The permanganate oxidation of humic acids extracted from acids soils. Soil Science 114, 185-193.

Maximov O. B., Shvets T. V. and Elkin Yu. N. (1977) On permanganate oxidation of humic acids. Geoderma 19, $63-78$.

Merlet D. (1971) Mise au point tecnique concernant l'extraction et la caractérisation des composés organiques dans les sols. Centre de Pédologie Biologique, C.N.R.S., Nancy, Doc. 15, 19 pp.

Monnier G., Turc L. and Jeanson Luusinang C. (1962) Une méthode de fractionnement densimétrique par centrifugation des matières organiques du sol. Annales Agronomiques 13, 55-63.
Schnitzer M. (1974) The methylation of humic substances Soil Science 117, 94-102.

Schnitzer M. and Khan S. U. (1972) Humic Substances in the Environment. Dekker, New York.

Simoneit B. R. T. and Mazurek M. A. (1982) Organic matter in the troposphere-II. Natural background of biogenic lipid matter in aerosols over the rural western United States. Atmospheric Environment 16, 2139-2159.

Simoneit B. R. T., Halpern H. I. and Didyk B. M. (1980) Lipid productivity of a high Andean lake. In Biogeochemistry of Ancient and Modern Environments (P. A. Trudinger, M. R. Walter and B. J. Ralph, Eds), pp. 201-210. Australian Academy of Sciences, Canberra.

Toutain F. (1974) Etude ecologique de l'humification dans les hêtraies acidiphiles. Doc. thesis, Univ. Nancy, France.

Vedy J. C. (1973) Relation entre le cycle biogeochimique des cations et l'humification en milieu acide. Doc. thesis, Univ. Nancy, France.

Waksman S. A. (1936) Humus, Origin, Chemical Composition and Importance in Nature. Williams \& Wilkins, Baltimore. 